\title{
Chlordiazepoxide-induced reversal of an amphetamine-established aversion: Dipsogenic effects
}

\author{
ANTHONY L. RILEY \\ The American University, Washington D.C. 20016 \\ and \\ RICHARD H. LOVELY
}

Department of Rehabilitative Medicine, University of Washington, Seattle, Washington 98195

\begin{abstract}
Chlordiazepoxide attenuated conditioned taste aversions if given prior to a one-bottle aversion test but had no effect if given prior to a two-bottle choice between water and the previously poisoned solution, suggesting that the attenuation resulted from chlordiazepoxide's dipsogenic effect, independent of its reported disinhibitory effects on suppressed behavior. These results were discussed in relation to general assessments of chlordiazepoxide's antipunishment effects on fluid-motivated baselines.
\end{abstract}

In a recent report (Cappell \& Leblanc, 1973), it was demonstrated that an aversion to a solution previously paired with amphetamine was attenuated by the administration of chlordiazepoxide $30 \mathrm{~min}$ prior to the aversion test. Under similar conditions (Cappell, LeBlanc, \& Endrenyi, 1972), chlordiazepoxide weakened a LiCl-established conditioned aversion, suggesting that the effect of chlordiazepoxide on food aversions was a function of some general process (Cappell \& LeBlanc, 1977), and independent of any specific drug interaction, e.g., chlordiazepoxide with amphetamine or chlordiazepoxide with $\mathrm{LiCl}$.

Cappell and LeBlanc (1973) suggested that the weakening by chlordiazepoxide of food aversions was a function of the general disinhibitory or antipunishment effect of chlordiazepoxide on suppressed behavior (Margules \& Stein, 1967). This interpretation has received considerable attention in the food aversion literature (Braveman, 1975; Bures \& Burešova, 1978; Gamzu, 1977; Mitchell, Fairbanks, \& Laycock, 1977), primarily when an attempt is made at elucidating a possible stress or emotional substrate for food aversions. However, although chloriazepoxide clearly affects suppressed or punished behavior (McKearney, 1973; Miczek \& Lau, 1975), the drug-induced attenuation of food aversions can also be explained in terms of a second property of chlordiazepoxide, i.e., the drug's dipsogenic effects (Bacotti \& Barrett, 1976; Barrett \& Weinberg, 1975;

The authors would like to thank E. Gamzu, V. M. LoLordo, and D. A. Zellner for their helpful criticisms. Requests for reprints should be sent to Anthony L. Riley, Department of Psychology, The American University, Washington, D.C. 20016.
Frontali, Amorico, Acetis, \& Bignami, 1976; Maickel \& Maloney, 1973; Poschel, 1971).

This dipsogenic effect of chlordiazepoxide is quite general and can be indexed by a number of measures (Poschel, 1971; Soubrie, De Angelis, Simon, \& Boissier, 1976), in a number of different environmental settings (Soubrie et al., 1976), under a number of states of deprivation (Miczek, 1973; Poschel, 1971), under operant, free-choice, or adjunctive schedules (Bacotti \& Barrett, 1976; McKearney, 1973; Miczek \& Lau, 1975), and with a variety of fluids, both novel and familiar (Miczek, 1973; Poschel, 1971; Soubrie et al., 1976; Gamzu, Note 1). It appears, therefore, that under a wide variety of conditions (only a few of which have a suppressed or inhibited fluid baseline), chlordiazepoxide is quite effective in increasing the rat's normal level of fluid consumption.

This dipsogenic property of chlordiazepoxide has a specific relationship to the chlordiazepoxide-induced attenuation of aversions reported by Cappell and LeBlanc (1973) and Cappell et al. (1972). As demonstrated by Cappell and LeBlanc (1973), animals readily acquire an aversion to a previously poisoned solution. Although typically resistant to a variety of experimental manipulations (Riley \& Clarke, 1977), taste aversions are substantially weakened by procedures, both behavioral and physiological, which increase the rat's baseline consumption, e.g., increased deprivation (Grote \& Brown, 1973), schedule-induced polydipsia (Roll, Schaeffer, \& Smith, 1969), and ventromedial hypothalamic lesions (Gold \& Proulx, 1972). This parallel suggests that chlordiazepoxide's attenuating effect on taste aversions may be a function of this peripheral dipsogenic effect and relatively 
independent of the proposed central, disinhibitory or antipunishment effect on suppressed behavior (Cappell \& LeBlanc, 1973; Margules \& Stein, 1967).

In an attempt to assess this alternative interpretation, the effects of chlordiazepoxide were examined on nonsuppressed drinking (Experiment 1) and suppressed drinking in a paradigm insensitive to dipsogenic stimulation (Experiment 2).

\section{EXPERIMENT 1}

Prior to assessing the interpretation that chlordiazepoxide-induced attenuation of food aversions is a result of chlordiazepoxide's dipsogenic effects, it is necessary first to demonstrate that chlordiazepoxide is dipsogenic under conditions similar to those in which the chlordiazepoxide-induced attenuation was initially reported (Cappell \& LeBlanc, 1973). Although chlordiazepoxide increases the general level of fluid consumption (see above summary), the effects of chlordiazepoxide on fluid consumption have not been systematically analyzed under these specific parameters (Cappell \& LeBlanc, 1973). Experiment 1 assessed chlordiazepoxide's dipsogenic effects under these conditions.

\section{Method}

Subjects. The subjects were 12 experimentally naive, female rats of Wistar descent, approximately 70 days of age. All subjects were maintained on a 12 -h-light/12-h-dark cycle for the duration of the experiment.

Apparatus. The subjects were housed in individual wire-mesh cages. In the front of each cage were two openings into which graduated Nalgene tubes were placed for presentation of water or saccharin solution ( $1 \mathrm{~g} /$ liter $)$.

Procedure. Following a 21-day adaptation period to individual housing, during which time food and water were continuously available, the subjects were deprived of all water and subsequently given a 10-min daily exposure to water for 5 consecutive days. On Day 6, all subjects were given a 10-min exposure to saccharin in place of water during the daily drinking session. Five minutes following the 10-min drinking period, all subjects were given an intraperitoneal injection (IP) of physiological saline $(.9 \%)$. On Days 7 and 8, the subjects were again given 10-min access to water. On Day 9, saccharin again replaced water during the usual 10-min drinking period.

Following this second exposure to saccharin, all subjects were returned to the daily 10 -min exposures to water for 4 consecutive days (Days 10-13). On the next day (Day 14), differential treatment was administered to two groups of subjects. Group $\mathrm{C}$ was given an IP injection of chlordiazepoxide $(5.0 \mathrm{mg} / \mathrm{kg}) 30 \mathrm{~min}$ prior to a 10-min exposure to saccharin. Group S was given an IP injection of physiological saline 30 min prior to a 10 -min exposure to saccharin. This manipulation was a test of the effects of chlordiazepoxide on the nonsuppressed drinking of a saccharin solution.

\section{Results}

Groups S and C both drank approximately $11 \mathrm{cc}$ of water on the final day of water adaptation. There was no significant difference between the two groups at this point in training $[\mathrm{t}(10)=0.78$, n.s.]. When saccharin was presented in place of water, both groups showed a small, but nonsignificant, drop in absolute consumption $[\mathrm{t}(5)=1.58$ and 0.21 , n.s., for Groups C and S, respectively], with neither group differing significantly from each other $[\mathrm{t}(10)=1.02$, n.s.].

The day following the saccharin presentation, each group returned to its previous water baseline (Day 5). When saccharin was presented on Day 9, all animals significantly increased their saccharin consumption above their initial saccharin baseline, with neither group drinking significantly different amounts. When water was reinstated (Days 10-13), both groups again returned to their previous water baseline. On Day 14, following the administration of saline (Group S) and chlordiazepoxide (Group C), Group C drank significantly more saccharin than Group S, 18.6 and $12.5 \mathrm{cc}$, respectively $[\mathrm{t}(10)=4.57, \mathrm{p}<.01]$. Group $\mathrm{S}$, which had been given saline $30 \mathrm{~min}$ prior to saccharin access, did not drink a significantly different amount of saccharin on this test (Day 14) from that of its Day 9 saccharin baseline $[\mathrm{t}(5)=1.26$, n.s.]. On the other hand, Group $C$, which had received chlordiazepoxide 30 min prior to saccharin access, significantly increased its saccharin consumption on this test above its Day 9 saccharin baseline $[\mathrm{t}(5)=3.38, \mathrm{p}<.01]$ (see Figure 1).

\section{Discussion}

Although chlordiazepoxide has been demonstrated to be dipsogenic under a variety of conditions (Bacotti \& Barrett, 1976; Barrett \& Weinberg, 1975; Gamzu, 1977; Poschel, 1971; Soubrie et al., 1976), the specific conditions under which chlordiazepoxide attenuated food aversions (Cappell \& LeBlanc, 1973) have not been examined. As suggested, prior to assessing the interpretation that the chlordiazepoxideinduced attenuation of food aversions is a result of chlordiazepoxide's dipsogenic effect, it is necessary

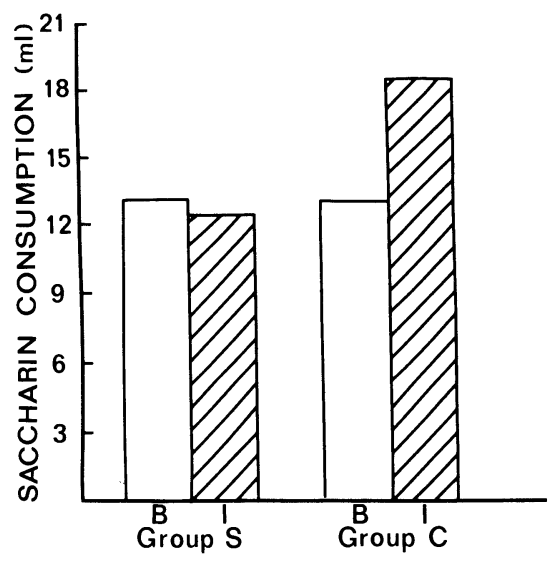

Figure 1. Mean saccharin consumption on the last saccharin baseline day, Day 9, (B) and following either saline or chlordiazepoxide injection (I) for Groups S and C. 
first to demonstrate that chlordiazepoxide increases levels of consumption under these conditions.

Similar to these earlier reports and under conditions similar to those in which the drug-induced attenuation was initially reported (Cappell \& LeBlanc, 1973), rats receiving chlordiazepoxide significantly increased fluid consumption above their own baselines as well as above the level of saline-pretreated subjects, extending further the generality of chlordiazepoxide's dipsogenic effects.

\section{EXPERIMENT 2}

The fact that chlordiazepoxide consistently increases the rat's baseline fluid consumption in a variety of experimental settings suggests that chlordiazepoxide's attenuating effect on taste aversions is less a function of the postulated disinhibitory property of chlordiazepoxide and more a result of chlordiazepoxide's dipsogenic effects.

In Cappell and LeBlanc's (1973) original demonstration of the chlordiazepoxide-induced attenuation of food aversions, chlordiazepoxide's effect on food aversions was assessed by a one-bottle test. Since chlordiazepoxide is dipsogenic, animals may have had a strong tendency to drink and the only solution to drink was the previously poisoned solution.

A number of researchers have demonstrated that one-bottle tests are generally less sensitive than twobottle tests in measuring food aversions (Dragoin, McCleary, \& McCleary, 1971; Elkins, 1973; Grote \& Brown, 1971; Klein, Domato, Hallstead, Stephens, \& Mikulka, 1975). For example, animals whose consumption of a particular solution is followed by poison, on a subsequent exposure drink significantly more of the previously poisoned solution if it is the only solution available (one-bottle test) than if it is given in a choice with water (two-bottle test).

The following experiment examined the effect of chlordiazepoxide on conditioned food aversions. This effect was assessed on both one- and twobottle tests. If chlordiazepoxide's attenuating effect on food aversions is a function of chlordiazepoxide's disinhibitory effect on suppressed or inhibited behavior, then aversions should be attenuated by chlordiazepoxide in both one- and two-bottle designs. If, however, the attenuating effect of chlordiazepoxide is a function of chlordiazepoxide's dipsogenic properties, only aversions assessed by a one-bottle test should be attenuated. Aversions assessed by a two-bottle test in which subjects have an alternative to the previously poisoned solution should be relatively unaffected by chlordiazepoxide. Experiment 2 tested these predictions.

\section{Method}

Subjects. The subjects were 22 experimentally naive female rats of Wistar descent, approximately 70 days of age at the beginning of the experiment. The subjects were maintained on a 12-h-light/12-h-dark cycle for the duration of the experiment.

Apparatus. The subjects were housed in individual wire-mesh cages. In the front of each cage were two openings into which Nalgene tubes were placed for presentation of water and/or saccharin ( $1 \mathrm{~g} /$ liter $)$.

Procedure. Following a 21-day adaptation period to individual housing, during which time food and water were continuously available, the subjects were deprived of all water and subsequently given a 10 -min daily exposure to water for 5 consecutive days. On Day 6, all subjects were given a 10-min exposure to saccharin in place of water during the daily drinking session. Five minutes following the 10-min drinking period, all subjects were given an IP injection of d-amphetamine sulfate $(2.0 \mathrm{mg} / \mathrm{kg})$. On Days 7 and 8 , the subjects were again given $10-\mathrm{min}$ access to water. On Day 9, saccharin was presented for $10 \mathrm{~min}$ in a one-bottle test of the aversion to saccharin.

Following this test, the subjects were returned to the daily 10-min exposure to water for 4 consecutive days (Days 10-13). On the next day (Day 14), all subjects were injected IP with $5.0 \mathrm{mg} / \mathrm{kg}$ chlordiazepoxide (Librium, Roche Laboratories) $30 \mathrm{~min}$ prior to their usual drinking time. At this point, the subjects were randomly divided into two groups. Group 1 was given a 10-min exposure to saccharin in a one-bottle test of the aversion to the saccharin solution. Group 2 was given a $10-\mathrm{min}$ exposure to both saccharin and water in a two-bottle test of the aversion to the saccharin solution.

\section{Results}

Both Groups 1 and 2 drank approximately $10 \mathrm{cc}$ of water on the final day of water adaptation. There were no significant differences between the two groups at this point in training $[\mathrm{t}(20)=1.70$, n.s.]. When saccharin was presented in place of water, both groups showed a small, but nonsignificant, drop in absolute consumption [t $(21)=1.32$, n.s.], with neither group differing significantly from each other $[\mathrm{t}(20)=0.91, \mathrm{n} . \mathrm{s}$.$] .$

The day following the amphetamine treatment, each group returned to its previous water baseline. When saccharin was presented for the one-bottle aversion test, all animals significantly decreased their saccharin consumption below their initial saccharin baseline $[\mathrm{t}(21)=3.59, \mathrm{p}<.01]$. The two groups, however, were not different from each other [ $t(20)$ $=1.12$, n.s.]. When water was reinstated (Days 10-13), both groups again returned to their previous water baseline.

On Day 14, following the administration of chlordiazepoxide, a significant difference emerged between the two groups of subjects on the total amount of saccharin consumed. Group 1, which was given a 10-min exposure to saccharin only, significantly increased its consumption of saccharin above the amount consumed on the first one-bottle aversion test, Day $9[\mathrm{t}(10)=9.02, \mathrm{p}<.01]$ (see Figure 2). This attenuation of the aversion is consistent with that reported by Cappell and LeBlanc (1973). Group 2, however, which was given both water and saccharin on Day 14 did not significantly change its consumption of saccharin following chlordiazepoxide administration $[\mathrm{t}(10)=2.01$, n.s.]. Group 2 preferred 


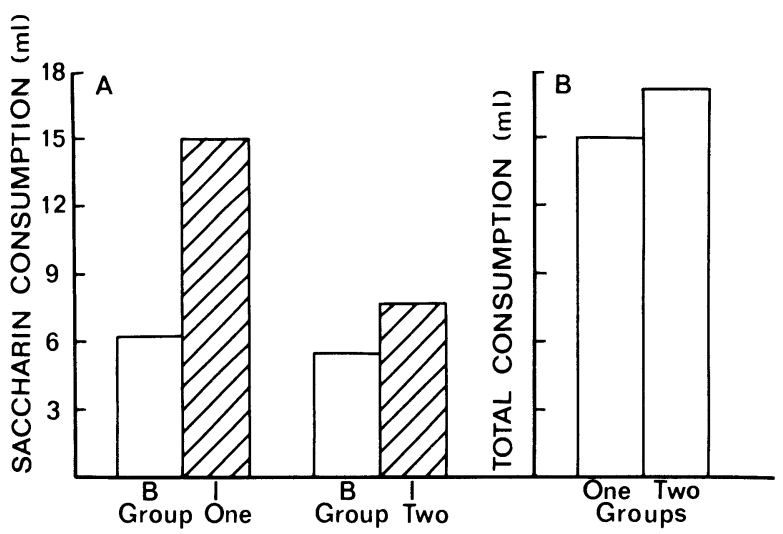

Figure 2. (A) Mean saccharin consumption on the initial aversion test, Day 9 (B) and the second aversion test, Day 14, following chlordiazepoxide injection (I) for one-bottle and two-bottle groups. (B) Mean total fluid consumption (saccharin for Group 1; saccharin and water for Group 2) following chlordiazepoxide injection.

water to saccharin on this two-bottle choice, drinking approximately 9.5 and $7.7 \mathrm{ml}$ of water and saccharin, respectively. On this test, Group 1 drank significantly more saccharin than Group $2[\mathrm{t}(20)=$ $4.95, \mathrm{p}<.01$ ] (see Figure 2). While for all animals the total fluid consumed on this test (saccharin for Group 1; saccharin and water for Group 2) was greater than the previous day's water baseline [ $\mathrm{t}(21)$ $=4.32, \mathrm{p}<.01]$, there was no significant difference between groups in the total amount of fluid consumed on this test $[\mathrm{t}(20)=1.81, \mathrm{n} . \mathrm{s}$.].

\section{Discussion}

It is clear from the data that chlordiazepoxide attenuated the conditioned aversion to a previously poisoned solution when it was the only available solution. While this attenuation is in empirical agreement with Cappell and LeBlanc (1973), the fact that chlordiazepoxide did not attenuate aversions when measured by a two-bottle test suggests that the attenuation in the one-bottle test design is not the result of any disinhibitory property of chlordiazepoxide on suppressed behavior (Cappell \& LeBlanc, 1973; Margules \& Stein, 1967).

That chlordiazepoxide's effect on food aversions is a function of the testing design suggests that chlordiazepoxide's dipsogenic property may be responsible for the original attenuation of conditioned aversions. Animals injected with chlordiazepoxide had an increased tendency to drink with only the previously poisoned solution available. In the present experiment, when animals were given an alternative during the aversion test, chlordiazepoxide produced no attenuating effect, i.e., aversions remained intact.

In addition to the present results, this dipsogenic property of chlordiazepoxide can possibly be media- ting or contributing to any antipunishment effect chlordiazepoxide has on paradigms utilizing fluidmotivated baselines. In a report addressing this possible confound of dipsogenic stimulation in the assessment of chlordiazepoxide's antipunishment effect, Maickel and Maloney (1973) noted that the effects of chlordiazepoxide are often examined on suppressed drinking, schedule-induced polydipsia, and water-reinforced operant responding. As in the present experiment, increases in consumption could reflect dipsogenic stimulation rather than or in addition to any potential disinhibitory effects of chlordiazepoxide.

\section{REFERENCE NOTE}

1. Gamzu, E. Personal communication, 1977.

\section{REFERENCES}

Bacotti, A. V., \& BARrett, J. E. Effect of chlordiazepoxide on schedule controlled responding and schedule induced drinking. Pharmacology, Biochemistry, and Behavior, 1976, 4, 299-304.

Barrett, J. E., \& Weinberg, E. S. Effects of chlordiazepoxide on schedule induced water and alcohol consumption in the squirrel monkey. Psychopharmacologia, 1975, 40, 319-328.

Braveman, N. S. Formation of taste aversions in rats following prior exposure to sickness. Learning and Motivation, 1975, 6, 512-534.

Bureš, J., \& BUREŠova, O. Physiological mechanisms of conditioned food aversion. In N. W. Milgram, L. Krames, $\&$ T. Alloway (Eds.), Food aversion learning. New York: Plenum Press, 1977.

Cappell, H. D., \& LeBlanc, A. E. Punishment of saccharin drinking by amphetamine in rats and its reversal by chlordiazepoxide. Journal of Comparative and Physiological Psychology, 1973, 85, 97-104.

Cappell, H. D., \& LeBlanc, A. E. Gustatory avoidance conditioning by drugs of abuse: Relationships to general issues in research on drug dependence. In N.W. Milgram, L. Krames, \& T. M. Alloway (Eds.), Food aversion learning. New York: Plenum Press, 1977.

Cappell, H. D., LeBlanc, A. E., \& Endrenyi, L. Effects of chlordiazepoxide and ethanol on the extinction of a conditioned taste aversion. Physiology \& Behavior, 1972, 9, 167-169.

Dragoin, W., McCleary, G. E., \& McCleary, P. A comparison of two methods of measuring conditioned taste aversions. Behavior Research Methods \& Instrumentation, 1971, 3, 309-310.

Elkins, R. L. Individual differences in bait shyness: Effects of drug dose and measurement technique. Psychological Record, 1973, 23, 349-358.

Frontali, M., Amorico, L., Acetis, L. D., \& Bignami, G. A pharmacological analysis of processes underlying differential responding: A review and further experiments with scopolamine, amphetamine, lysergic acid diethylamide (LSD), chlordiazepoxide, physostigmine, and chlopromazine. Behavioral Biology, 1976, 18, 1-74.

GAMzU, E. The multifaceted nature of taste-aversion inducing agents: Is there a single common factor? In L. M. Barker, M. Best, \& M. Domjan (Eds.), Learning mechanisms in food selection. Waco, Texas: Baylor University Press, 1977.

Gold, R. M., \& Proulx, D. M. Bait-shyness acquisition is impaired by VMH lesions that produce obesity. Journal of Comparative and Physiological Psychology, 1972, 79, 201-209.

Grote, F. W., JR., \& Brown, R. T. Conditioned taste aversions: Two-stimulus tests are more sensitive than one-stimulus 
tests. Behavior Research Methods \& Instrumentation, 1971, 3, 311-312.

Grote, F. W., JR., \& BRown, R. T. Deprivation level affects extinction of a conditioned taste aversion. Learning and Motivation, 1973, 4, 314-319.

Klein, S. B., Domato, G. C., Hallstead, C., Stephens, I., \& Mikulka, P. J. Acquisition of a conditioned aversion as a function of age and measurement technique. Physiological Psychology, 1975, 3, 379-384.

Maickel, R. P., \& Maloney, G. J. Effects of various depressant drugs on deprivation-induced water consumption. Neuropharmacology, 1973, 12, 777-782.

Margules, D. L., \& Stein, L. Neuroleptics vs. tranquilizers: Evidence from animal behavior studies of mode and site of action. In H. Brill, J. O. Code, P. Deniker, H. Hippius, \& P. B. Bradley (Eds.), Neuropsychopharmacology. Amsterdam: Excerpta Medica Foundation, 1967.

MCKearney, J. W. Effects of methamphetamine and chlordiazepoxide on schedule controlled and adjunctive licking in the rat. Psychopharmacologia, 1973, 30, 375-384.

MiczeK, K. A. Effects of scopolamine, amphetamine, and chlordiazepoxide on punishment. Psychopharmacologia, 1973, 28, 373-389.

MiczeK, K. A., \& LAU, P. Effects of scopolamine, physostigmine, and chlordiazepoxide on punished and extinguished water consumption in rats. Psychopharmacologia, 1975, 42, 263-269.

Mitchell, D., Fairbanks, M, \& Laycock, J. D. Suppression of neophobia by chlorpromazine in wild rats. Behavioral Biology, 1977, 19, 309-323.

Poschel, B. P. H. A simple and specific screen for benzodiazepine-like drugs. Psychopharmacologia, 1971, 19, 193-198.

Riley, A. L., \& Clarke, C. M. Conditioned taste aversions: A bibliography. In L. M. Barker, M. Best, \& M. Domjan (Eds.), Learning mechanisms in food selection. Waco, Texas: Baylor University Press, 1977.

Roll, D., Schaeffer, R. W., \& SMith, J. C. Effects of a conditioned taste aversion on schedule-induced polydipsia. Psychonomic Science, 1969, 16, 39-41.

Sanger, D. J., \& Blackman, D. E. The effects of chlordiazepoxide on the development of adjunctive drinking in rats. Quarterly Journal of Experimental Psychology, 1975, 27, 494-505.

Soubrie, P., De Angelis, L., Simon, P., \& Boisser, J. R. Effets des anxiolytiques sur la prise de boisson en situation nouvelle et familière. Psychopharmacology, 1976, 50, 41-45.

(Received for publication April 20, 1978; revision accepted June 19,1978 .) 